\title{
Comparison of Shadow Economies: The Case of Ghana, Nigeria and UK
}

\author{
Dennis Nchor ${ }^{1}$ \\ Václav Adamec ${ }^{2}$ \\ Pavel Kolman ${ }^{3}$ \\ 1/ng., Mendel University, Faculty of Business and Economics, Department of Statistics and Operations Analysis \\ Zemědělská 1, 61300 Brno, Czech Republic. Email: xnchor1@node.mendelu.cz \\ ${ }^{2}$ Associate Professor, Mendel University, Faculty of Business and Economics, Department of Statistics and Operations Analysis \\ Zemědělská 1, 61300 Brno, Czech Republic.Email: vadamec@mendelu.cz \\ ${ }^{3}$ Ph.D., Mendel University, Faculty of Business and Economics, Department of Statistics and Operations Analysis \\ Zemědělská 1, 61300 Brno, Czech Republic. Email: xkolman@mendelu.cz
}

\section{Doi:10.5901/mjss.2016.v7n1p248}

\section{Abstract}

This study seeks to assess the size and the trend of the shadow economies of Ghana, Nigeria and the United Kingdom. The multiple indicator and multiple causes model (MIMIC) is employed for this analysis. The model consists of two parts; the structural equation aspect and the measurement aspect. The structural equation model estimates the impact of the observed variables in determining the level of shadow economic activities. The measurement model estimates the coefficients of the indicator variables. Results from the study show variation in the causal factors of shadow economic activities in the various countries. The size of Ghana's shadow economy stands at $36.73 \%$, Nigeria $47.75 \%$ and UK, $15.05 \%$ at the end of the 2012 fiscal year. The average level of such activities for the past three decades is $30.20 \%$ of the official economy in Ghana, $50.36 \%$ in Nigeria and $14.07 \%$ in UK.

Keywords: shadow economy, multiple indicator and multiple causes model, structural equation, underground economy, unregistered businesses, tax evasion.

\section{Introduction}

Underground economic activities are present in all economies of the world. In developing countries, however, they are especially established. Their presence stands behind numerous economic and social problems, although it is not necessarily harmful for the affected economies, since it provides additional opportunities for employment and extra income to the impoverished population. Despite its unofficial nature, unreported economic activities add increments to gross domestic product and thus improve economic performance. They appear to prevail in sectors of economies, which demand a lot of labor, such as services, agriculture, construction and retail sectors. Shadow economy may, on the other hand, cause huge losses to government revenues and could also constitute serious violations of labor, health and safety regulations and lead to various distortions of the labor market.

Numerous definitions of the shadow economy were previously formulated in the literature (Ogbuabor and Malaolu 2013; Schneider et al. 2010). It is often described either as economic activity associated with production and dissemination of products or services that are strictly sanctioned by the law; or activity that is in principal legal, however, it remains unreported to the authorities with the purpose of tax evasion, noncompliance with regulations or avoidance of official bureaucracy. Economic units involved in grey activities operate without the constraints of behavior prescribed by the public authorities, although own internal rules and regulations may also exist (Oduh et al. 2008). The relationship of the informal sector with the official economy still remains incomprehensively described, although some authors claim that rising official economy weakens underground activities, as both compete for the same resources (Ogbuabor and Malaolu 2013).

The hidden nature of the underground economy creates difficulties in quantifying the extent and dynamics of activities, as well as understanding the underlying causes, which may be specific in wealthy technology-driven economies or in developing countries of the third world with prevailing agriculture or raw material production. It is widely accepted that, size of economic output (GDP) per capita, general level of taxation and social security payments, size of the government consumption, extent of business regulation (see Johnson, Kaufmann, and Zoido-Lobatón 1998b), quality of 
public administration, unemployment rate, inflation at the consumer level, corruption index and self-employment rate contribute to the proportion of shadow economies. For studies which found that found statistically significant evidence of the influence of taxation on the shadow economy, see studies of Schneider (2007) and Johnson, Kaufmann and ZoidoLobatón $(1998 a, 1998 b)$. Other studies in support of this assertion were done by Kirchgaessner $(1983,1984)$ and Klovland (1984).

Since, the informal economy is concealed; its presence can be inferred indirectly from indicator variables of the labor market, monetary segment or state of the official economy. Labor force participation is an indicator for measuring shadow economic activities, since proportion of the economically active population changes with growing shadow economy. Thus a negative relationship is anticipated between the shadow economy and labor force participation in the official economy. People, who are engaged in unofficial activities, tend to keep large quantum of cash outside the banking system to avoid leaving traces of their transactions. Hence growing shadow economy is always reflected in an additional use of cash or currency. For this reason, the ratio of cash outside the banking system to the volume of broad money (M2) is positively correlated with the size of the shadow economy. The growth rate of GDP per capita is also involved in influencing the extent of the shadow economies, because growing GDP per capita in an economy indicates improvement in well-being of the population. This could imply a declining incentive to participate in shadow economic activities.

The objective of this study is to estimate the size and trend of the shadow economies for two developing African countries (Ghana and Nigeria) and one advanced economy, the United Kingdom (UK). The choice of countries is based on the fact that both Ghana and Nigeria have similar economic structures and will help bring out the similarities. UK was added due to the fact that it has an advanced economy and will also help bring out the contrasts between developing and advanced economies with regards to the causes and the actual size of shadow economic activities.

\section{Materials and Methods}

Stimation of the MIMIC model and the follow up diagnostics were completed with STATA software version 12 (StataCorp 2011). Yearly time series analyzed in this study were received from the World Bank country indicators and from the International Financial Statistics. All variables were first order differenced to remove non-stationarity properties i.e. variables were integrated of order one, I(1).

In the past, numerous approaches have been considered to estimate the shadow economy. Out of many, the Currency Demand approach (Ariyo and Bekoe 2011; Faal 2003) and the Multiple Indicators and Multiple Causes model (MIMIC) by Schneider and Enste (2000) and Schneider et al. (2010) were the most favored.

\subsection{Multiple Indicators and Multiple Causes Model}

Multiple Indicators and Multiple Causes model (MIMIC) is a variant of the Simultaneous Equations Model (SEM). It received its name from pioneering researchers in the field such as (Jöreskog and Goldberger 1975), although it had previously been discussed by others for example Zellner (1970) and Hauser - Goldberger (1971).

It has two parts: the structural equation model and the measurement model. The first component estimates the relationship between the causal variables and the latent variable, which represents the informal economy. The following equation shows the relationship between individual causal variables and shadow economic activities in each specific country.

$\eta_{t}=\alpha_{1} X_{1 t}+\alpha_{2} X_{2 t}+\alpha_{3} X_{3 t}+\alpha_{4} X_{4 t}+\alpha_{5} X_{5 t}+\alpha_{6} X_{6 t}+\alpha_{7} X_{7 t}+\varepsilon_{t}$

In the structural equation model, $\eta_{t}$ is the latent variable (informal economy) and $\alpha_{1}, \alpha_{2}, \ldots, \alpha_{7}$ are the model coefficients. Symbols $X_{1}, X_{2}, \ldots, X_{7}$ denote exogenous causal regressors determining the size of the latent variable. The latent variable is directly unobserved, but it can be estimated from the MIMIC model.

The measurement model alternatively estimates the impact of the shadow economy on each indicator variable. The measurement model is given by equation (2).

$y_{t}=\beta \eta_{t}+\varepsilon_{t}$

Where $y_{t}=\left(y_{1}, y_{2} \ldots, y_{n}\right)$ is a $(1 \times n)$ vector of the indicator variables, $\beta$ represents the regression coefficients and $\varepsilon_{t}$ is a $(1 \times n)$ vector of errors satisfying the white noise.

\subsection{MIMIC Index}

First, for each country, the MIMIC model is correctly specified and its parameters are subsequently estimated by the method of Maximum Likelihood (ML). The general structure of the MIMIC model is illustrated in Figure 1. 


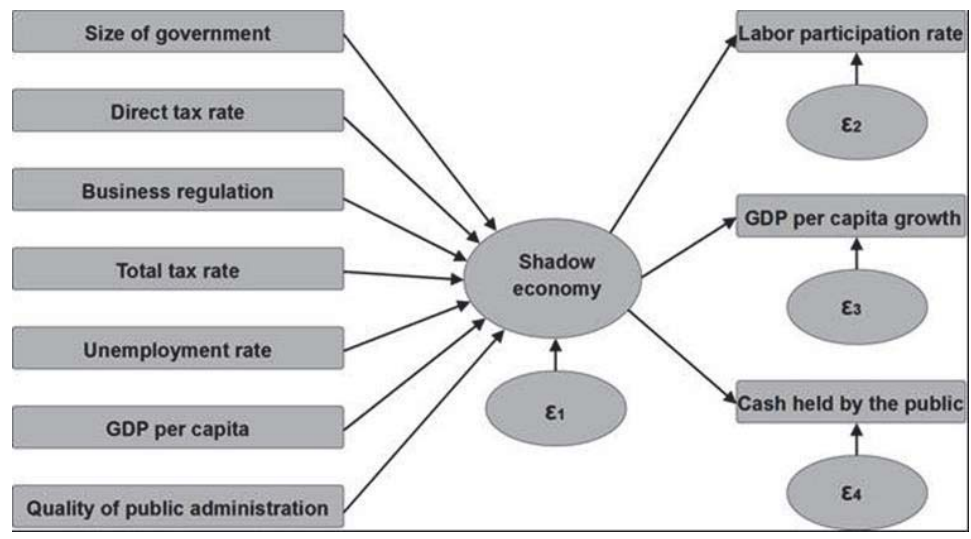

Figure 1. The structure of the MIMIC model

Source: Author generated

The causes and indicator variables provided may slightly differ among models for specific countries. During the diagnostic stage the analyst verifies parameter significance $(\alpha=0.10)$ and ensures that the SEM model meets criteria of good fit (StataCorp 2011). Later the parameter estimates are used to predict the latent variable (underground economy) and calculate the MIMIC index (\%) from it (Schneider et al. 2010).

$$
\hat{\eta}_{t}=\frac{\widetilde{\eta}_{t}}{\widetilde{\eta}_{1983}} \eta_{1983}^{*}
$$

In equation (3), $\hat{\eta}_{t}$ is the calculated MIMIC index at time $t$; it estimates the shadow economy as percentage of the official economy; $\tilde{\eta}_{t}$ is the estimated value of the latent variable at time $t ; \tilde{\eta}_{1990}$ is the estimate of the shadow economy in the base year 1983 and $\eta_{1983}^{*}$ is the exogenous estimate of the shadow economies in 1990. Exogenous shadow economy is the exterior estimate, i.e. base value of the shadow economies in 1983, derived for each country as the average size of the shadow economy from several previous studies. A line plot of the MIMIC index finally displays the trend of the underground economy.

\section{Results}

This aspect of the paper analyses the results obtained from the estimation of both the structural equation model and the measurement model. Results are presented and explained in series of tables and figures. The analysis begins with the Ghanaian economy, followed by the Nigerian economy and then the economy of the United Kingdom. Probability values criterion (P-values) is used in determining the level of significance of variables. P-values lower than $5 \%$ indicates a rejection of the null hypothesis of parameter insignificance.

The quality of the results from the model was checked using goodness of model fit criteria for general structural equation models (SEM). The included the Residual Mean Square Error of Approximation (RMSEA), Comparative Fit Index (CFI), Coefficient of Determination (CD), Multiple Correlation Coefficient (MC) and the Standard Root Mean Square Residual (SRMR). The requirement for a good structural equation model is that RMSEA $<0.05, \mathrm{CFI} \geq 0.90, \mathrm{SRMR}<0.05$ and CD $\geq 0.90$. Hu - Bentler (1999), Kenny, Kaniskan, McCoach (2014), MacCallum, Browne and Sugawara (1996) further explained these quality criteria.

\subsection{Shadow economic activities in Ghana}

The results for Ghana are illustrated in Tab. 1. Direct tax rate, size of government, total tax rate, and the rate of unemployment proved statistically significant in influencing shadow economic activities. The expected signs of the coefficients of direct tax rate and the size of government were not met. The negative sign in the coefficient of direct tax rate could be attributed to the low tax base currently and the expansion in the economy. With low tax rates and low tax base, the impact of a marginal increase in direct taxes will have a negligible impact on the economic decisions of households. The results also show that increasing size of government leads to declining shadow economic activities. This 
could be attributed to the small size of government currently. An increase therefore in the size of government will improve efficiency leading to a decline in shadow economic activities.

The results show that an increase in direct tax rate by a percentage point leads to a decline in shadow economic activities by $0.26 \%$. It also reduces by $0.31 \%$ in the case of a percentage point growth in the size of government. An increase in total tax rates by a percentage point leads to an increase in shadow economic activities by $0.40 \%$ and it also increases by $0.17 \%$ for every percentage point increase in the rate of unemployment. The results are displayed in Tab. 1.

Table 1. Structural equation results for Ghana

\begin{tabular}{llcccc}
\hline Structural & Labor force participation & Coefficient & Std. Err & t-ratio & P-value \\
\hline & Shadow economy & \multicolumn{2}{c}{1 (constrained) } & & \\
& Unemployment rate & -0.10 & 0.04 & -2.57 & 0.01 \\
& Constant & 64.33 & 4.44 & 14.49 & $<0.01$ \\
\hline Shadow economy & & & & \\
& Direct tax rate & -0.26 & 0.08 & -3.22 & $<0.01$ \\
& Size of government & -0.31 & 0.13 & -2.41 & 0.02 \\
& Total tax rates & 0.40 & 0.12 & 3.34 & $<0.01$ \\
& Unemployment rate & 0.17 & 0.05 & 3.38 & $<0.01$ \\
\hline
\end{tabular}

LR test of model vs. saturated: $\chi_{2}^{2}=1.28, P\left(>\chi_{2}^{2}\right)=0.53$, Labor participation rate is constrained to a value of 1 .

\subsubsection{Goodness of fit statistics (Ghana)}

From Tab. 2, 83\% of the variation in the dependent variables is explained by the model variables. Given the results in Tab. 2, the SEM model for Ghana meets the criteria for a good model fit. Thus the results are used for the analysis of shadow economic activities.

Table 2. Goodness of fit statistics (Ghana)

\begin{tabular}{|c|c|c|c|c|c|}
\hline Population error & Statistic & & & & \\
\hline RMSEA & 0.00 & & & & \\
\hline Pclose & 0.55 & & & & \\
\hline \multicolumn{6}{|l|}{ Baseline comparison } \\
\hline $\mathrm{CFI}$ & 1.00 & & & & \\
\hline \multicolumn{6}{|l|}{ Size of residuals } \\
\hline $\begin{array}{l}\text { SRMR } \\
\text { CD }\end{array}$ & $\begin{array}{c}0.018 \\
0.88 \\
\end{array}$ & & & & \\
\hline Dependent variable & Fitted & Variance Predicted & Residual & R-squared & $\mathrm{MC}$ \\
\hline \multicolumn{6}{|l|}{ Observed } \\
\hline Labor participation rate & 4.16 & 1.98 & 2.18 & 0.48 & 0.69 \\
\hline Cash holding by public & 0.01 & 0.01 & $<0.01$ & 0.62 & 0.79 \\
\hline \multicolumn{6}{|l|}{ Latent } \\
\hline Shadow economy & 2.26 & 1.89 & 0.37 & 0.83 & 0.91 \\
\hline
\end{tabular}

\subsection{Shadow Economic Activities (Nigeria)}

Shadow economic activities in Nigeria from the study are caused by the size of government, total tax rate, the unemployment rate, the quality of public sector services and business regulation as shown in Tab. 3. The expected signs of coefficients were realised for all variables. The results show that the size of the shadow economy grows by $0.05 \%$ for every percentage point increase in the size of government. It also grows by $0.20 \%, 0.04 \%$ and $0.39 \%$ in the case of percentage points increases in the total tax rate, unemployment rate and business regulation respectively. It reduces by $0.81 \%$ for every percentage point increase in the quality of public sector services. Labor participation rate and growth in GDP per capita are the main indicators of shadow economic activities in Nigeria. The results are displayed in Tab. 3. 
Table 3. Structural equation for Nigeria

\begin{tabular}{|c|c|c|c|c|c|}
\hline \multirow[t]{6}{*}{ Structural } & Labor force participation & Coefficient & Std. Err & t- ratio & P-value \\
\hline & Shadow economy & \multicolumn{4}{|c|}{1 (constrained) } \\
\hline & Constant & 49.03 & 3.10 & 15.81 & $<0.01$ \\
\hline & GDP per capita growth & & & & \\
\hline & Shadow economy & -16.96 & 7.26 & -2.34 & 0.02 \\
\hline & Constant & 129.75 & 73.69 & 1.76 & 0.08 \\
\hline \multicolumn{6}{|c|}{ Shadow economy } \\
\hline & Size of government & 0.05 & 0.02 & 2.82 & 0.01 \\
\hline & Total tax rates & 0.20 & 0.08 & 2.33 & 0.02 \\
\hline & Unemployment rate & 0.04 & 0.01 & 4.40 & $<0.01$ \\
\hline & Quality of public administration & -0.81 & 0.20 & -4.14 & $<0.01$ \\
\hline & Business Regulation & 0.39 & 0.19 & 2.12 & 0.03 \\
\hline & Constant & 129.75 & 73.69 & 1.76 & 0.08 \\
\hline
\end{tabular}

Likelihood ratio test of model vs. saturated: $\chi_{4}^{2}=2.05, P\left(>\chi_{4}^{2}\right)=0.73$.

\subsubsection{Goodness of fit statistics (Nigeria)}

Tab. 4 shows the detailed picture of SEM fit for Nigeria. The model meets the quality criteria required for structural equation modeling.

Table 4. Goodness of fit statistics (Nigeria)

\begin{tabular}{|c|c|c|c|c|c|}
\hline Population error & $\begin{array}{l}\text { RMSEA } \\
\text { Pclose }\end{array}$ & $\begin{array}{l}0.00 \\
0.75\end{array}$ & & & \\
\hline Baseline comparison & $\mathrm{CFI}$ & 1.00 & & & \\
\hline Size of residuals & $\begin{array}{l}\text { SRMR } \\
\text { CD }\end{array}$ & $\begin{array}{l}0.03 \\
0.90\end{array}$ & & & \\
\hline Dependent variable & Fitted & Variance predicted & Residual & R-squared & $\mathrm{MC}$ \\
\hline $\begin{array}{l}\text { Observed } \\
\text { Labor force participation rate } \\
\text { GDP per capita growth }\end{array}$ & $\begin{array}{c}0.51 \\
786.9\end{array}$ & $\begin{array}{c}0.47 \\
136.42\end{array}$ & $\begin{array}{c}0.04 \\
650.47\end{array}$ & $\begin{array}{l}0.92 \\
0.17\end{array}$ & $\begin{array}{l}0.96 \\
0.42\end{array}$ \\
\hline $\begin{array}{l}\text { Latent } \\
\text { Shadow economy }\end{array}$ & 0.47 & 0.423 & 0.05 & 0.90 & 0.95 \\
\hline
\end{tabular}

Ghana and Nigeria have similar causal variables for shadow economic activities. Size of government, total tax rates and the level of unemployment are factors common to both countries. In the case of the indicators, the amount of cash held by the public is a significant indicator of shadow economic activities in Ghana unlike in Nigeria. Both countries have labor participation rate serving as a good indicator for detecting the presence of shadow economic activities. The other indicator in the case of Nigeria is the growth in GDP per capita.

\subsection{Shadow economic activities (UK)}

Results from the study show that shadow economic activities in UK are caused by the size of government, unemployment rate, and self-employment rate. Its presence is indicated by the amount of cash held outside the banking system and the level of growth of GDP per capita. As expected, the study results show that an increase in the size of government by a percentage point leads to growth in shadow economic activities by $0.35 \%$. The sign of coefficient for unemployment from the result is however negative indicating that an increase in the level of unemployment by a percentage point leads to a reduction in shadow economic activities by $0.22 \%$. This is probably taking into account the social transfer system such as subsidies and other welfare benefits. It might be an indication that there is a higher motivation to stay unemployed given 
the kind of jobs available to the individual so as to enjoy social benefits which could be comparatively higher. The results also show that an increase in self-employment by a percentage point leads to growth in shadow economic activities by $0.32 \%$. This is a clear indication that there is a higher tendency for self-employment activities to avoid the official system. It might be due to a lapse in the intensity of regulation. Tab. 5 shows the details.

Table 5. Structural equation model (UK)

\begin{tabular}{llcccc}
\hline Structural & GDP per capita growth & Coefficient & Std. Err & t-ratio & P-value \\
\hline & Shadow economy & -0.002 & 0.001 & -4.55 & $<0.01$ \\
& Unemployment rate & -0.33 & 0.18 & -1.84 & 0.07 \\
& Constant & 28.25 & 5.65 & 5.00 & $<0.01$ \\
\hline Shadow economy & & & & & \\
\hline & Size of Government & 353.23 & 45.44 & 7.77 & $<0.01$ \\
& Unemployment rate & -222.33 & 30.88 & -7.2 & $<0.01$ \\
& Self-employment rate & 319.37 & 72.81 & 4.39 & $<0.01$ \\
\hline
\end{tabular}

Likelihood ratio test of model vs. saturated: $\chi_{2}^{2}=0.08, P\left(>\chi_{2}^{2}\right)=0.96$, Cash held by the public was constrained to an intercept of 1 in the case of UK

\subsubsection{Goodness of fit statistics}

Tab. 4 shows the detailed picture of SEM fit for UK. The model meets the quality criteria required for structural equation model.

Table 6. Goodness of fit statistics (UK)

\begin{tabular}{|c|c|c|c|c|c|}
\hline Population error & Criteria & Statistic & & & \\
\hline & RMSEA & 0.00 & & & \\
\hline & Pclose & 0.96 & & & \\
\hline \multicolumn{6}{|l|}{ Baseline comparison } \\
\hline & CFI & 1.00 & & & \\
\hline \multicolumn{6}{|l|}{ Size of residuals } \\
\hline & SRMR & 0.01 & & & \\
\hline & $C D$ & 0.98 & & & \\
\hline Dependent variable & Fitted & Variance predicted & Residual & R-squared & $\mathrm{MC}$ \\
\hline \multicolumn{6}{|l|}{ Observed } \\
\hline GDP per capita growth rate & 4.88 & 2.39 & 2.50 & 0.49 & 0.70 \\
\hline Cash holding by public & 686993.60 & 585852.30 & 101141.30 & 0.85 & 0.92 \\
\hline \multicolumn{6}{|l|}{ Latent } \\
\hline Shadow economy & 585852.30 & 573021.40 & 12830.91 & 0.98 & 0.99 \\
\hline
\end{tabular}

\subsection{Computation of the actual size and trend in shadow economic activities (Ghana, Nigeria and UK)}

The actual size and trend in shadow economic activities are estimated using the MIMIC index as used by Schneider et al (2010). The index is calculated for each of the countries i.e. by multiplying the coefficients of the significant causal variables with the respective time series (see equation 3). This index is converted into absolute values of the shadow economies. The base values necessary for this final step of the calibration procedure are from the year 1983.The base year exogenous values assumed for each country based on the average size of their shadow economies from several studies include: $42 \%$ for Ghana, 56\% for Nigeria and 12\% for UK. The results are displayed in Fig. 2. 


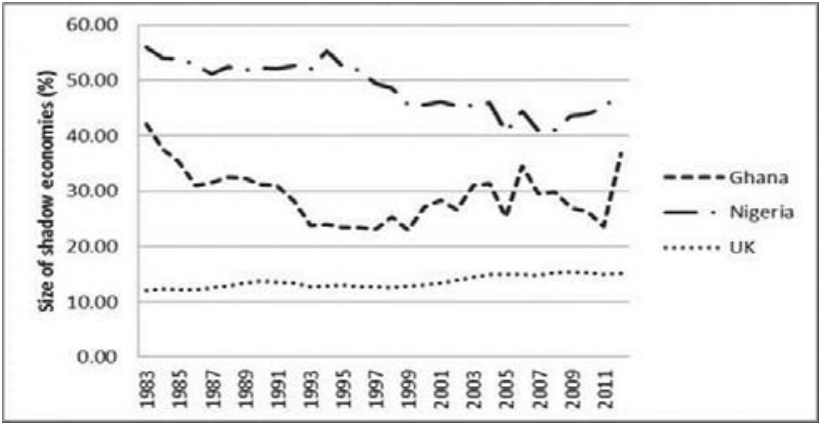

Figure 2. Trend in Shadow economies of the three countries

The results displayed in Fig. 2 show the UK economy recording the lowest shadow economic activities compared to Ghana and Nigeria. The general trend in activities in Ghana and Nigeria is a declining one except for few cases of intermittent peaks. A steady upward trend is observed in the case of Nigeria from 2007 where it can be attributed to the global economic crises. In the case of Ghana, shadow economic activities increased sharply from 2011 which can be largely attributed to several businesses which sprang up as a result of the commercial production of oil in 2010. Shadow economic activities in the UK have been increasing steadily from 1999. The effect of the global financial meltdown is also observed though its impact is marginal.

The results show that the size of the shadow economy in Ghana is about $36.73 \%$ as at the end of the 2012 fiscal year, $47.75 \%$ and $15.05 \%$ of the official economies in Nigeria and UK respectively. The size of government and the level of unemployment rate are consistent causal variables in all the countries. The level of total tax rates is a common variable in both Ghana and Nigeria. Nigeria however has extra factors understandably the quality of public sector administration and the level of business regulation. UK has an additional factor which is the level of self-employment.

\subsubsection{Estimated average level of shadow economic activities}

Fig. 3 shows the average size of shadow economic activities as a percentage of official GDP in all the three countries. Ghana has an average size of $30.20 \%$ of its economic activities hidden from the official economy. In the case of Nigeria and UK, the sizes are $50.36 \%$ and $14.07 \%$ respectively.

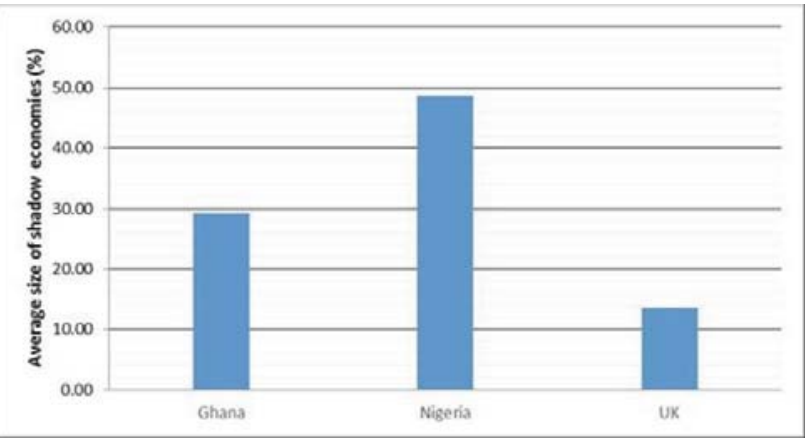

Figure 3. Average size of the shadow economies (1983-2013)

\section{Discussion}

Shadow economies have socio-economic impacts which are often not healthy. Their (shadow economies) presence are closely linked to several activities such as corruption, drug trade, labor exploitation, environmental hazards and the violation of human rights. They affect policy making as the true size of the economies are often not estimated. 
Transactions in this kind of economy are difficult to monitor also making it virtually impossible for taxation. It must however be stated that though the negative factors offset the positives, there are a few good effects which include the fact that shadow economies serve as a source of income for the excess labor force. The other effect is that income earned in this economy is spent on the official economy.

According to the study by Schneider (2012) using the MIMIC approach, the average level of shadow economic activities in sub-saharan Africa was about $40.2 \%$ which contains both Ghana and Nigeria. His study also estimates a mean level of $17.1 \%$ for high income OECD countries where the United Kingdom belongs. Schneider and Buehn (2010) estimated an average size of $12.5 \%$ for UK. The estimated average size from this study as at the end of the 2012 fiscal year is $15.05 \%$.

Ogbuabor and Malaolu (2013) estimated the size and causes of the shadow economy in Nigeria using an error correction MIMIC model. Their results showed that the informal economy of Nigeria hovered around 53.6- 77.2\% of GDP since 1970 and that the average size of the informal economy was about $64.6 \%$ of GDP. This study however estimates an average of about $50.36 \%$.

Elgin and Oztunali (2012) using a two-sector dynamic general equilibrium model estimated the shadow economies around the world. Their study estimates an average of about $23.61 \%$ for OECD countries and $42.9 \%$ for countries in subSaharan Africa.

A study by Ariyo and Bekoe (2011) employed the currency demand approach to derive estimates for the size of the underground economy and the magnitude of tax evasion. The results from their study showed that the size of the shadow economy ranged between $42.5 \%-79.3 \%$ in Nigeria and Ghana. The study also established a positive relationship between underground economy and tax evasion. These results are in tandem with the estimated averages for both Ghana and Nigeria by this study.

Dell' Anno (2007) similarly used the MIMIC approach to estimate the shadow economy of Portugal. The results from his study showed that the shadow economy ranges from 29.6 percent, in 1978, to 17.6 percent of official GDP in 2004. This is similar to the results for UK and comparison is made because both countries belong to OECD.

\section{Consequences of Shadow Economies}

Shadow economies are one of the causes of an inefficient functioning of the goods and labor markets. Prices of factors of production and goods and services cannot be monitored. This thus distorts market equilibrium. Labor supply services at wages below the minimum wage. It therefore harms workers because they are deprived of their rights and guarantees.

State revenue is also largely affected as a result of the decision by businesses to work outside the official system. In Ghana and Nigeria especially where the size of such activities relative to the official economy is very large, the state loses high quantum of tax revenue. In most cases governments run budget deficits.

Corruption increases as a result of the hidden nature of these activities. Any activity that is not registered increases the tendency for malpractices.

It affects policy making as the national accounts aggregates are not reliable. With such high percentage of production not accounted for in the estimation of GDP, estimates of a country's national accounts become less credible and could lead to wrong policy formulation. Such activities also produce environmental hazards which are not accounted for in the estimation of national accounts.

On the positive side it creates value addition which is spent on the official economy. It also bridges the income distribution gap as people with low income undertake such activities to supplement their low earnings. For countries with high unemployment rates and lack of social welfare systems such as unemployment benefits, these underground activities help reduce the adverse effects as long as the activities are legal.

\section{Recommendations}

As much as shadow economic activities have negative effects on the official system, they also have positive ones as observed. Policy formulation should therefore be focused on moving such activities into the formal sector and not to eliminate them. This initiative can be achieved by thoroughly investigating the main causes of such activities, the actual size and their distribution by economic sectors.

The size of government and the total tax rate should be reduced. The size of government in all three countries might be too large for such economies. It only promotes inefficiency and duplication of roles. Corruption is a by-product of this development. The tax rate on corporate institutions is too high which is driving businesses into the shadow economy. The focus should be on widening the tax base instead of increasing the tax rate. With the public sector employing as low 
as about $15 \%$ of the total labor force in the case of Ghana and currently freezing employment initiatives, unemployment will certainly rise and this will only drive individuals into shadow economic activities as a means of survival. An enabling environment should therefore be created for more investment both domestic and foreign driven to open up the economy in terms of job opportunities. Bureaucracy and structural bottle necks which hamper the development of the private sector should be streamlined.

There is the need for improvement in the quality of public sector services in Nigeria as it proved to be a significant cause of shadow economic activities. Perceptions of an inefficient public sector will only drive individuals and businesses into hidden activities.

Intensity of business regulation has the tendency to either reduce or increase shadow economic activities depending on how it is enforced. If the rules and laws set serve to deprive individuals and businesses of their freedom of choice, shadow economic activities will increase. Therefore the focus should be on enforcement.

Self-employment is one cause of shadow economic activities which has a magnificent positive effect on the official economy. It reduces the adverse effects of unemployment and its related social vices. It also provides income which is spent on the official economy. In the case of UK, such activities prove to be highly found within the hidden economy. That implies huge loss to government in terms of state revenue. Efforts should therefore be made to draft such activities into the mainstream official economy.

\section{Conclusion}

The goal of this study is to assess the size and trend of the shadow economies in Ghana, Nigeria and UK. This was done using the multiple indicator multiple causes model. The study observed that shadow economic activities are strongly persisistent and prevalent within the three economies under study.

Ghana and Nigeria have high GDP growth rates which should lead to a reduction in the level of shadow economic activities. In the case of Ghana, growth rate virtually doubled as a result of the addition of oil proceeds. It could therefore be argued that growth in both countries is not socially inklusive. In other words, it is not equitably distributed but only benefits a small proportion of the population which are often the elites. It could therefore be observed that oil production in Ghana rather led to growth in shadow economic activities.

With regards to Nigeria, the population is quite large and the necessary infrastructure is lacking. Most economic activities therefore escape official detection.

The standard of living in the United Kingdom is high as compared to Ghana and Nigeria. The UK economy is however exposed to immigrants from different parts of the world. Such a development only leads to growth in shadow economic activities if not well monitored.

The study applied only the MIMIC approach unlike other studies which compared the results of two models. Unemployment benefits remain one of the variables used by other studies but adding this variable will tantamount to duplication as the effect of unemployment rate was captured in the model.

As controversial as some of the causal variables may be, the study could not use corruption and bribery as it was difficult to obtain adequate data for both Ghana and Nigeria.

Subsidies and other social welfare schemes play a large role in determining whether individuals participate in shadow economic activities or not. This could be well documented for UK but less likely in the case of Ghana and Nigeria. The study did not therefore use this variable.

The estimated impact of the shadow economy on government tax revenue cannot be overemphasized. Higher shadow economic activities indicate huge losses in terms of revenue mobilization. With an average size of $30.20 \%$, $50.36 \%$ and $14.07 \%$ of the official economy in Ghana, Nigeria and UK the leakage in terms of state revenue is enormous which thus requires stringent policies to ameliorate the situation.

\section{Acknowledgement}

The author appreciates the financial support from Mendel University's Internal Grant Agency (IGA) which made the study possible. The output of this paper thus forms part of the IGA project No. 35/2014.

\section{References}

Ariyo, A., \& Bekoe, W. (2011). Currency demand, the underground economy and tax evasion: the case of Nigeria. Journal of Monetary and Economic Integration, 11 (2), 129-157. 
Dell'anno, R. (2007). The shadow economy in Portugal: an analysis with the Mimic Approach. Journal of Applied Economics, 5(2), 253277.

Elgin, C., \& Oztunali, O. (2012). Shadow economies around the world: model based estimates. Bogazici University Working Papers.

Faal, E. (2003). Currency demand, the underground economy and tax evasion - the case of Guayana. IMF Working Paper.

Hauser, R. M., \& Goldberger, A. S. (1971). The treatment of unobservable variable in path analysis. In Costner, H. L., ed., Sociological Methodology, San Francisco. Jossey Bass.

Hu, L., \& Bentler, P. M. (1999). Cutoff criteria for fit indexes in covariance structure analysis: conventional criteria versus new alternatives. Structural Equation Modeling, (6), 1-55.

Johnson, S., Kaufmann, D., \& Zoido-Lobatón, P. (1998A). Regulatory discretion and the unofficial economy. The American Economic Review, 88 (2), 387-392.

Johnson, S., Kaufmann, D., \& Zoido-Lobatón, P. (1998B). Corruption, public finances and the unofficial economy. The World Bank Discussion Paper.

Jöreskog, K. G., \& Goldberger, A. S. (1975). Estimation of a model with multiple indicators and multiple causes of a single latent variable. Journal of the American Statistical Association, 70 (351), 631-639.

Kenny, D. A., Kaniskan, B., \& Mccoach, D. B. (2014). The performance of RMSEA in models with small degrees of freedom. Sociological Methods \& Research.

Kirchgaessner, G. (1983). Size and development of the west German shadow economy, 1955- 1980. Zeitschrift Für Die Gesamte Staatswissenschaft, 139 (2), 197-214.

Kirchgaessner, G. (1984). Verfahren zur erfassung des in der schattenwirtschaft erarbeiteten sozialprodukts. Allgemeines Statistisches Archiv, 68 (4), 378-405.

Klovland, J. (1984). Tax evasion and the demand for currency in Norway and Sweden: is there a hidden relationship. Scandinavian Journal of Economics, 86 (4), 423-439.

Maccallum, R. C., Browne, M. W., \& Sugarawa, H. M. (1996). Power analysis and determination of sample Size for covariance structure modeling. Journal of Psychological Methods, 130-149.

Oduh, M., et al. (2008). Measurement and explanation of informal sector of the Nigerian economy. African Institute for Applied Economics Research Paper, (3), 1-64.

Ogbuabor, J.E., \& Malaolu, V. A. (2013). Size and causes of the informal sector of the Nigerian economy: evidence from error correction Mimic model. Journal of Economics and Sustainable Development, 4 (1).

Schneider, F., \& Enste, D. (2000). Shadow economies: size, causes, and consequences. The Journal of Economic Literature, 38 (1), $77-114$.

Schneider, F., Buehn, A., \& Montenegro, C.E. (2010). Shadow economies all over the world - new estimates for 162 countries from 1999 to 2007. World Bank Policy Research Working Paper No. 5356.

Schneider, F., \& Enste, D. (2000). Shadow economies: size, causes, and consequences. The Journal of Economic Literature, 38 (1), 77-114.

Schneider, F. (2007). Shadow economies and corruption all over the world: new estimates for 145 countries' economies. The OpenAccess, Open-Assessment E-Journal, 1.

Schneider, F. (2012). Size and development of the shadow economy of 31 European and 5 other OECD countries from 2003 to 2012: some new facts.

STATACORP. (2011). Stata Statistical Software Release 12 College Station. TX USA: StataCorp LP.

Zellner, A. (1970). Estimation of regression relationships containing unobservable variables. International Economic Review, 11 (1), 441454. 